\title{
In Memory of Yu. P. Irkhin
}

DOI: $10.1134 / \mathrm{S} 0031918 X 09120151$

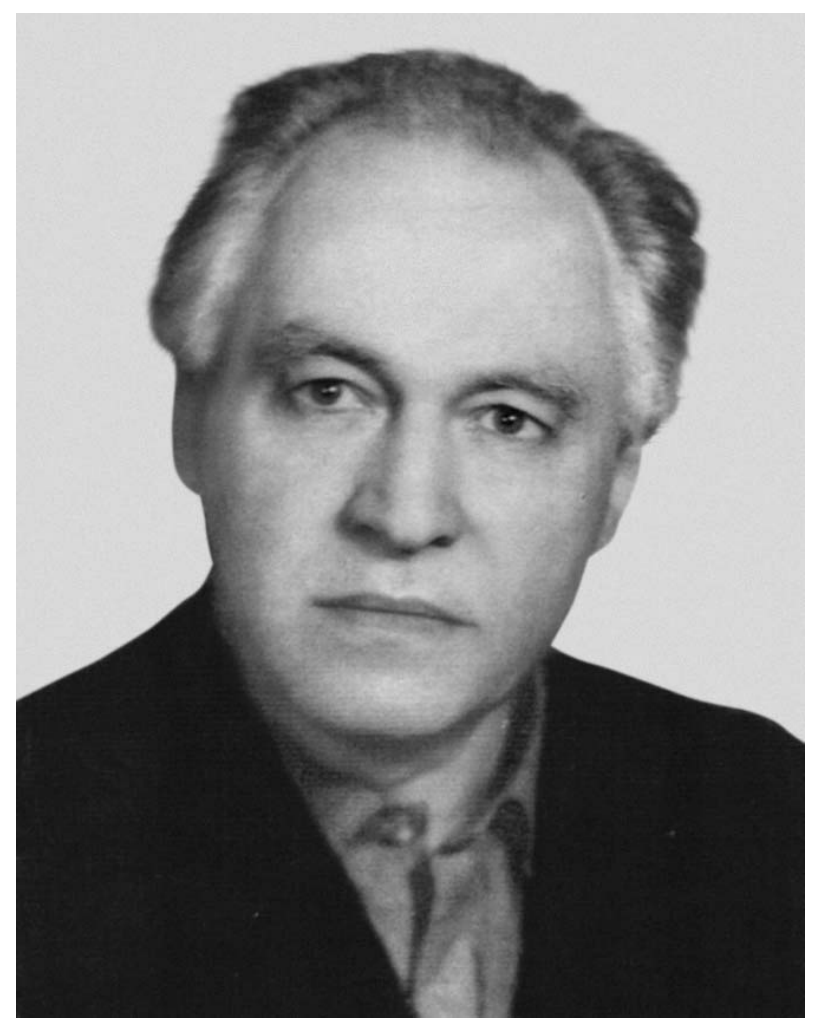

On January 28, 2009, Professor Yurii Pavlovich Irkhin, Chief Scientist of the Institute of Metal Physics, Ural Division, Russian Academy of Sciences, passed away ...

After he graduated with honors from the Saratov University in 1953, he moved to Sverdlovsk (now Ekaterinburg) and became a graduate student at the Institute of Metal Physics. In the first years, he received much from the collaboration with S. V. Vonsovskii and E. A. Turov. In 1957, he defended a candidate dissertation and in 1967, a doctorate dissertation, which was devoted to the relationship between the electrical and magnetic characteristics of solids. In 1984, Yurii Pavlovich received a State Prize for the researches in the magnetism of rare-earth metals and their compounds. In 1988-1996, he was head of the Laboratory of the Theory of Transition Metals; for many years he delivered lectures on the physics of metals at the Ural State University and at the Ural Polytechnic Institute.
In the last years, which were shadowed by a grave illness, Yurii Pavlovich did not interrupt his activity in science. Up to his last days, he felt obliged to take part in discussions on physics with his colleagues, retained a quick and clear spirit and sense of humor.

He published about 100 original and review papers on the solid-state theory and physics of metals in leading Russian and international journals, as well as a large monograph devoted to the electronic properties of transition metals (which was translated into English and published by the Cambridge International Science Publishing). The results of his works (e.g., concerning the explanation of magnetic anisotropy of rare-earth systems, theory of anomalous kinetic effects in metals, etc.) undoubtedly will remain in the world physics.

Editorial Staff 